\title{
La importancia de las Artes en la educación de la nación y el individuo
}

\section{The importance of Arts in the Education of the Individual and Society}

\section{Antonio Blanco Pérez*}

* Profesor titular en la Universidad de La Habana (Cuba). Es Licenciado en Historia, Doctor en Ciencias Económicas y profesor titular de Sociología, Filosofía y Economía de la Educación. Autor de libros y artículos publicados en Cuba, Ecuador y México. Ha impartido docencia en programas de maestría y doctorado desarrollados en Cuba, Brasil, Bolivia, República Dominicana y Ecuador. Miembro del Tribunal de Doctorado del Instituto Central de Ciencias Pedagógicas de Cuba durante 15 años, tutor de 25 tesis de doctorado defendidas en Ciencias Pedagógicas y de la Educación. Ha recibido diversas condecoraciones profesionales y actualmente es Metodólogo del Archivo Central de la Universidad de La Habana. Correo electrónico: ablanco@rect.uh.cu

D https://orcid.org/0000-0002-1484-6694

\section{Historial editorial}

Recibido: 19-agosto-2019

Aceptado: 14-diciembre-2019

Publicado: 31-enero-2020

ISSN-e: 2594-2956 
La importancia de las Artes en la educación de la nación y el individuo

\section{Resumen}

La definición del arte (o de las artes, si así se prefiere) no es un asunto resuelto, por cuanto no existe unanimidad en cuanto a su consideración como mímesis, o sea, reproducción del mundo en imágenes artísticas, aceptable en el caso de la literatura y las artes plásticas, (incluso en el cine) pero más difícil de admitir en otras expresiones, como la música o la danza. Desde una concepción filosófica materialista (extensa y diversa) se define el arte como una forma específica de la conciencia social y de la actividad humana, históricamente condicionada, un reflejo subjetivo de la realidad objetiva a través de imágenes artísticas, que constituye uno de los procedimientos más importantes del proceso de aprehensión estética del mundo. Así entendido, el arte resulta no solo un contenido de la educación del ser humano, sino también un medio para educarlo, para ampliar su visión del mundo y de sí mismo, desde la perspectiva de los valores estéticos, que condicionan sus criterios y actitudes ante el arte. El presente trabajo pretende analizar, desde esa perspectiva filosófica, el papel del arte y de la educación estética y artística en el desarrollo de la cultura individual y social, de la nación y del individuo, su relación con el desarrollo económico de la sociedad y su incidencia en la formación integral del sujeto.

Palabras Clave: Arte, Educación Artística, Educación Estética, Valores, Criterios, Actitudes y Sentimientos Estéticos. 


\section{The importance of Arts in the Education of the Individual and} Society

\section{Abstract}

There is no consensus among researchers on a definition of art or the Arts or if all art is mimetic by nature, that is, the idea that all art is the representation of the real world. The idea of art as being mimetic is allowed in the case of literature and plastic arts, even cinematography but is generally not acceptable in other artistic expressions, such as music or dance. The concept of Art from a materialist philosophical perspective (extensive and diverse) holds the idea that it is a specific form of social consciousness and human activity, historically determined and conditioned, a subjective reflection of objective reality through artistic images, which constitutes one of the most important components of the process of aesthetic apprehension of the world. But once this concept is granted, art becomes not just an academic subject but a means to educate, to broaden the human vision of the world and of the self, from the perspective of aesthetic values, which condition our criteria and attitudes towards art. This paper aims to analyze from this philosophical perspective, art, aesthetic, and arts education's role in the development of individual, social and national aspects of culture, their relationship with society and economic development, and their impact on integral human development.

Keywords: Art, Artistic Education, Aesthetic Education, Values, Approaches, Attitudes and Aesthetic Feelings 


\section{L'importance des arts dans l'éducation de la nation et de l'individu}

\section{Résumé:}

La définition de l'art (ou des arts, si l'on préfère) n'est pas un problème résolu, car il n'y a pas unanimité quant à sa prise en compte comme mimésis, c'est-à-dire la reproduction du monde en images artistiques, acceptable dans le cas de la littérature et les arts plastiques (même au cinéma) mais plus difficiles à admettre dans d'autres expressions, comme la musique ou la danse. D'une conception philosophique matérialiste (extensive et diversifiée), l'art est défini comme une forme spécifique de conscience sociale et d'activité humaine, historiquement conditionnée, une réflexion subjective de la réalité objective à travers des images artistiques, qui constitue l'une des procédures le plus important du processus d'appréhension esthétique du monde. Ainsi compris, l'art n'est pas seulement un contenu de l'éducation de l'être humain, mais aussi un moyen de l'éduquer, d'élargir sa vision du monde et de lui-même, dans la perspective des valeurs esthétiques, qui conditionnent ses critères et attitudes avant l'art. Cet article vise à analyser, dans cette perspective philosophique, le rôle de l'art et de l'éducation esthétique et artistique dans le développement de la culture individuelle et sociale, de la nation et de l'individu, leur relation avec le développement économique de la société et ses impact sur la formation intégrale du sujet.

Mots-clés: Art, Éducation Artistique, Éducation Esthétique, Valeurs, Critères, Attitudes et sentiments esthétiques, 
Znaczenie Sztuki w oswiacie: narodu i jednostki.

\section{Streszczenie:}

Definicja sztuki to caly nierozwiązany problem, ponieważ nie ma jednomyślności do jej zdefiniowania jako memezy, czyli reprodukcji świata w obrazach artystycznych, dopuszczalne w przypadku literatury i sztuki plastycznej, (nawet w kinie), ale znacznie trudniej jest wyrazic ja w takich kategoriach jak muzyka czy taniec. Od materialistycznej koncepcji filozoficznej (rozległej i zróżnicowanej) sztuka jest definiowana jako specyficzna forma świadomości społecznej i działalności człowieka, historycznie uwarunkowanej, subiektywne odbicie obiektywnej rzeczywistości poprzez obrazy artystyczne, które są jedną z najważniejszych procedur w procesie zatrzymania tworzenia i przetwarzania swiata. Tak rozumiana sztuka jest nie tylko treścią edukacji człowieka, ale także środkiem wychowania go, aby rozwinąć swoją wizję świata i siebie, z perspektywy wartości estetycznych, które warunkują jego kryteria i nastawienie do sztuki. Niniejszy dzieło ma na celu analizę, z filozoficznej perspektywy, roli sztuki oraz edukacji estetycznej i artystycznej w rozwoju kultury indywidualnej i społecznej, narodu i jednostki, jego relacji $z$ rozwojem gospodarczym społeczeństwa i wpływ na integralne kształtowanie się podmiotu.

Slowa kluczowe: Sztuka, educacja artystyczna, wartosci, kryteria, postawy i uczucia artystyczne. 


\section{Introducción}

El análisis del papel de las Artes (o como es más común, el Arte) en la vida de la sociedad pareciera innecesario, por cuanto nadie se atrevería a poner en duda el lugar de esa forma tan específica de la actividad humana, que permite el disfrute de obras de incuestionable valor estético, creadas a lo largo de la historia de la humanidad, capaces de producir sentimientos y sensaciones de placer y admiración en todos los que, de una u otra forma, acceden a ellas.

Sin embargo, como puede verificarse en la amplia literatura sobre el tema, la definición del arte (o de las artes, si así se prefiere) no es para nada un asunto resuelto, por cuanto no existe unanimidad en su consideración como mímesis (Walton, 1990), o sea, reproducción del mundo en imágenes artísticas, perfectamente aceptable en el caso de la literatura y las artes plásticas, pero más difícil de admitir en la música o la danza, la arquitectura y las artes decorativas (Dickie, 1974).

Dos definiciones surgidas en los inicios del siglo XX están construidas sobre el rechazo a la representación como característica definitoria del arte. La primera de ellas establece el arte como forma significativa, en tanto la segunda lo considera como expresión de emociones. Ambas rebajan la relación de la obra de arte (y por tanto, del artista) con la realidad, en favor de las cualidades estéticas del objeto artístico en sí mismo o de la relación entre la obra de arte y la mente creativa que la originó.

Estas consideraciones, de marcada filiación idealista, pueden encontrarse originalmente en las ideas de belleza y genio en la teoría

22 del arte de E. Kant. Tanto la definición que se centra en el objeto, como la que se orienta al artista, son utilizadas para discriminar lo que se admite como arte de lo que no lo es, y así han servido por mucho tiempo para admitir (o rechazar) los valores estéticos de diversas formas de arte progresivas. A pesar de esa intención legitimadora, cada una de estas definiciones resulta unidimensional $y$, por tanto, incompleta. 
La polémica sobre la definición del arte ha llegado al extremo de sugerir que el verdadero núcleo del concepto está en su ilimitada capacidad de aceptación del cambio. En contraposición, se ha propuesto una definición institucional del arte, movidos por la idea de que la única característica común entre las obras de arte es el hecho de que han sido reconocidas como tales por ciertas instituciones en determinado momento (Honderich, 200I). Será difícil negar que la inclusión o exclusión de diferentes obras en el estatuto del arte han cumplido otras funciones en la sociedad, como por ejemplo las de fomentar el elitismo o la diferencia de clases.

La definición institucional no siempre es muy convincente para demostrar lo que es particularmente valioso en el arte. A veces se asume que el arte (el producto) es bueno en la medida en que posee un valor puramente estético, con independencia del valor moral, cognitivo o utilitario que pueda poseer. Pero el arte es también importante como medio para adquirir comprensión de la conducta humana, el valor de los productos del arte no puede separarse de la esfera de la verdad y de la moral.

Desde una concepción filosófica materialista, que transcurre desde la ingenuidad del atomismo griego hasta la complejidad de los neomarxistas actuales, el arte es una forma específica de la conciencia social y de la actividad humana, históricamente condicionada. Consiste entonces en un reflejo subjetivo de la realidad objetiva a través de imágenes artísticas, que constituye uno de los procedimientos más importantes del proceso de aprehensión estética del mundo (Iudin y Rosenthal, I98I).

Esta definición se contrapone a las que, desde el idealismo objetivo hegeliano, consideran el arte como producto de la "voluntad universal" o de la "revelación divina", o las que partiendo del idealismo subjetivo neokantiano consideran el arte como el producto de las ideas y vivencias personales del artista, de su subconsciente, que se traducen en obras de arte gracias a su genialidad individual. 


\section{Desarrollo}

Las investigaciones históricas han demostrado que el origen de la actividad artística y de los sentimientos y necesidades estéticas está estrechamente vinculado con la actividad productiva, con la creación de bienes indispensables para la subsistencia, dicho más brevemente, con el trabajo.

Entre los pueblos primitivos, en época tan lejana como el Neolítico tardío, la relación entre el trabajo y la creación artística es directa e inmediata, se decoran las paredes de las cavernas, se elaboran collares y prendedores con los huesos y colmillos de los animales, se tallan figuras que representan el cuerpo humano o de los animales, incluso se pinta sobre el propio cuerpo humano, siempre con la intención de asegurar o agradecer una buena caza, una cosecha abundante o la protección contra los más diversos peligros.

La posibilidad de que la creación artística pudiera separarse de la actividad productiva es un resultado final de la división social del trabajo, que se había iniciado con la aparición de los oficios y la separación entre el trabajo manual y el intelectual. Solo en la medida en que el desarrollo de la productividad del trabajo permitió la aparición de excedentes fue posible que algunos individuos pudieran dedicarse a otras actividades no productivas, entre ellas, la creación de bienes que satisfacían necesidades de índole espiritual y no estrictamente material. ${ }^{\text {I }}$

Todas las grandes civilizaciones antiguas (Egipto, Mesopotamia, China e India) lo son tanto por el desarrollo alcanzado por las fuerzas productivas, de la base económica, como por los resultados que lograron en la superestructura de sus sociedades, dentro de la cual el arte ocupa un lugar tan distintivo como el de la religión o la organización del Estado.

Por tanto, la aparición del arte, como actividad independiente de la producción material, y de los artistas, individuos dotados de 
sensibilidad y habilidades específicas y dedicados exclusivamente a esa actividad, es un producto del desarrollo de la sociedad, tanto a nivel de la base económica como superestructural. Sin embargo, la relación entre ambos componentes de la sociedad no es mecánica. Mayor nivel de desarrollo económico y de riqueza material no significa necesariamente una mayor cantidad o calidad del arte y de sus productos, de la misma forma que en sociedades decadentes y en momentos de franco proceso de desaparición se han creado magníficas expresiones del arte más auténtico y trascendente. Esta aparente contradicción es un reflejo de la independencia relativa de las formas de la conciencia social respecto a la base económica que le da origen, cuestión suficientemente explicada por los teóricos del Materialismo filosófico (Lúkacs, 1963, Sánchez, 1980).

Llegado a este punto, es conveniente recordar que el arte es uno de los componentes más reconocidos de la cultura, aunque no el único. Una definición clásica de la cultura la identifica como el "conjunto de valores materiales y espirituales, así como de los procedimientos para crearlos, aplicarlos y transmitirlos, obtenidos por el hombre en el proceso de la práctica histórico social" (Iudin y Rosenthal, I98I, p. 98). En esta definición se hace distinción entre la cultura material, que incluye la técnica y la tecnología, la experiencia productiva y los bienes materiales producidos por ella, y la cultura espiritual, que abarca los resultados de la ciencia, el arte y la literatura, la filosofía, la política, la religión, el derecho, la moral, la instrucción, etc. Es incuestionable la existencia de una estrecha relación entre la cultura material y la espiritual, tanto como la existente entre todas las manifestaciones de la cultura y de ellas con el arte, lo que no las exime de contradicciones que no por evidentes resultan sencillas de resolver.

Como forma específica de la conciencia social, el arte está relacionado con la ciencia y la tecnología, que se manifiesta en la utilización de nuevos materiales naturales o artificiales, así como las técnicas y procedimientos que enriquecen y diversifican las formas de expresión artística, su divulgación y reproducción en los más diversos ambientes y portadores. La relación del arte con la ideología política se manifiesta 
tanto en el fundamento teórico como en la selección de los temas, la intencionalidad del mensaje contenido en la obra de arte, y aún más, en el compromiso personal del artista con la sociedad en la que vive y con la clase social a la que representa; cuestiones recogidas en lo que se denomina como carácter de clase del arte. La relación del arte con la moral es evidente en el tratamiento ético de los temas, por muy escabrosos que sean, en el respeto a la dignidad humana y en la representación de la verdad en todas sus creaciones, personajes o situaciones, por sobre cualquier otra consideración. La relación del arte con la economía es recurrente en los procesos de creación artística, que requieren de medios para su realización, en las vicisitudes de la difusión del arte, en la financiación de la formación artística, sea pública o privada, en el aseguramiento de los medios de subsistencia del artista, que le permitan la dedicación al arte o a su enseñanza y, en las condiciones actuales, los conflictos derivados de la mercantilización del arte, que atentan contra su calidad y pertinencia social. La relación del arte con la educación, en la que pretendemos centrar la atención, tiene su expresión en dos planos diferentes, pero relacionados entre sí; la educación artística y la educación estética.

Estas interrelaciones asumen formas muy particulares y distintivas en cada estadio de la historia de la humanidad, de tal modo que puede decirse que cada época genera su propia forma de expresar los valores estéticos, su manera de entender el concepto de la belleza y de reconocerlo en tal o cual producto de la actividad humana, así como la forma de divulgarlos y reproducirlos a través de la educación. Así, por ejemplo, en la Comunidad Primitiva el concepto de arte y de actividad artística estaba directamente relacionado con las necesidades de la sobrevivencia del grupo, y los posibles valores estéticos de los objetos 26 quedaban solapados por los valores utilitarios, en el sentido de servir como medio para asegurar las actividades productivas.

En el régimen esclavista el arte se independiza de la producción material y comienza a desplegar su poder simbólico, su capacidad para representar la realidad desde criterios de belleza: armonía, equilibrio, proporcionalidad y ritmo, que empiezan a definirse como categorías 
estéticas, virtudes que deben distinguir a los productos de una actividad que se realiza no ya para satisfacer necesidades materiales, sino del espíritu.

Las pirámides del Antiguo Egipto se construyen con el propósito declarado de guardar el cuerpo de los faraones, divinos por sí mismos, pero también con la intención no menos importante de demostrar el inmenso poder del monarca, capaz de poner en movimiento a toda la nación en la construcción de una obra tan colosal como inútil, en el sentido más estricto de la palabra. Las bellas obras de la arquitectura helenística, además de expresar el respeto a las deidades, sirven al fin más terrenal de propiciar el descanso y la conversación a los ciudadanos, que disponen del tiempo libre suficiente para dedicarse a cultivar su intelecto. La literatura y el teatro, como la música y la danza, contribuyen a esa educación, siempre restringida a la clase esclavista, interesada en la conservación y transmisión de los valores que le resultan necesarios, para ello se acude a la recreación de las tradiciones, a legitimar, mediante el arte, las desigualdades de una sociedad que encuentra su expresión sublimada en el mundo de la mitología. Los artistas son protegidos y premiados, (como también perseguidos y castigados) porque la aristocracia esclavista reconoce su papel dentro de la sociedad.

La Edad Media es el momento más adecuado para el desarrollo de las expresiones artísticas de carácter místico religioso. Esto es perfectamente comprensible si se toma en cuenta que el régimen de servidumbre ya no descansa tanto en la violencia física (como sí lo había hecho el esclavismo) sino preferentemente en la coerción ideológica, a través de la religión (cualquiera que esta sea), que justifica el orden establecido como expresión de la voluntad divina, a lo que solo corresponde la humildad y la resignación. El arte medieval es místico y grandioso en lo que se refiere a los temas y las obras, en tanto que oscuro y represivo en relación con el ser humano, considerado un instrumento de aquella voluntad superior. La Iglesia, mucho más que la aristocracia terrateniente por lo general bastante inculta, es la que 
patrocina el arte y por tanto es la que legitima los valores estéticos de tal o cual objeto, santificando o reprimiendo la obra del artista.

El surgimiento y desarrollo de las ciudades, terreno de las actividades mercantiles, y de las nuevas clases sociales relacionadas con ellas, tuvo su expresión en el arte renacentista, volcado a la expresión de los sentimientos humanos, a la terrenalidad y la búsqueda de la felicidad a través de los sentidos. No es de extrañar el cambio radical que se produce en los patrones estéticos, que tratan de apegarse más a la realidad, tanto en la expresión de la figura humana como de sus aspiraciones. La pintura se hace más realista, la arquitectura es más funcional, la literatura aborda personajes y situaciones cotidianas, la música y la danza comienzan a incorporar aires y pasajes de origen popular, la burguesía se abre paso como clase emergente y con ella introduce nuevos códigos estéticos, nuevas formas de entender el arte y también, por supuesto, nuevas formas de administrar y difundir lo que acepte como tal. Es este también el momento en que surgen las primeras teorías sobre la naturaleza del arte y el hecho artístico

El capitalismo establece las condiciones necesarias para el despliegue de la creación artística, libre de las múltiples ataduras que sufría en las épocas anteriores, pero sujeto ahora a las leyes del mercado, que convierten al arte en una mercancía más. La producción artística se convierte en un hecho comunicativo más que interpretativo, en un acto de lenguaje que puede resultar incomprensible para los neófitos, incapaces de comprender la semántica con la que opera un creador o un grupo creativo, que, sin embargo, goza del reconocimiento de los curadores, las academias o las casas de subasta (también puede ocurrir todo lo contrario, cuando una obra o un artista son rechazados por esas instancias, no por la carencia de valores estéticos, sino por razones ajenas al arte). El artista depende ahora de la comercialización de su obra, y cabe remedar la expresión socorrida de los investigadores... "o publicas o pereces", que para el artista se traduce en exponer en las galerías y eventos de renombre, grabar en las casas disqueras, actuar en los circuitos reconocidos, bailar en los teatros de mérito, etc., etc. La mercantilización del arte (y en consecuencia, del artista) expresión 
suprema de lo que Marx definió como "fetichización de la mercancía" ha conducido a lo que en el lenguaje postmoderno se le denomina "cultura del espectáculo", más interesada en el impacto performativo sobre el espectador que en el mensaje del autor, a veces completamente incomprensible para la media del público. Lo que en las definiciones originales parecía resumir la esencia del arte (la representación de la realidad mediante imágenes artísticas, portadoras del mensaje desde la visión subjetiva del artista) terminan por convertirse en ejercicios de incomunicación, carentes de significado para el común.

Los proyectos socialistas intentaron una reconceptualización del arte y del papel de los artistas desde la perspectiva del arte de y para las masas, lo que condujo a una demonización de todo o casi todo el arte calificado como "burgués" y por tanto reaccionario (Ovsianikov, I986) Sólo se salvaban de esta crítica las obras del naturalismo y las del denominado "realismo crítico" del siglo XIX y XX (Lúkacs, 1963). En contraposición, algunos intelectuales de la revolución bolchevique rusa-como A. Lunacharski- promovieron el concepto de "proletkult" para identificar a la cultura del proletariado, que debía sustituir a la de la burguesía derrotada. Años más tarde este concepto fue sustituido por el de "realismo socialista", no menos infeliz que el anterior (Navarro, I986), con el que se pretendía uniformar todo el arte revolucionario. No obstante, esa perniciosa desviación, el arte soviético pudo exhibir obras de reconocido valor estético y alto compromiso político, como la poética de Mayakovski, la novelística de Sholojov o el cine de Einseistein, pero no pudo evitar el aislamiento y la reprobación de otros artistas cuyas obras fueron catalogadas como perniciosas o contrarrevolucionarias: Pasternak, Ajmatova, Sochelnitzin, Evtuchenko, Tarkovski, que por lo tanto quedaban excluidas de los programas de enseñanza.

La Historia del Arte recoge el avatar de la actividad artística de la humanidad, de sus adelantos y retrocesos, de sus cultores y detractores, de la manera en que el reflejo artístico de la realidad se ha ido complejizando y enriqueciendo, incorporando nuevas formas $y$ técnicas, profundizando sus juicios y valoraciones, ampliando sus espacios y públicos. Como ya se explicó, la evolución del arte no es 
regular, ni reproduce exactamente los cambios que ocurren en la base económica de la sociedad ni en las otras formas de la vida de la sociedad, pero a través de esa historia se reconocen esos cambios, que dan lugar a las escuelas, tendencias y estilos predominantes en cada momento y lugar. En este sentido la historia del arte es también un formidable medio para la comprensión de la historia de la humanidad.

Se impone recordar que, desde la concepción del materialismo dialéctico, el arte se distingue de las otras formas de la conciencia social en cuanto a dos cuestiones fundamentales: su objeto y su objetivo. El objeto del arte lo constituyen las actitudes estéticas del ser humano frente a la realidad objetiva, sustentadas en criterios estéticos, o sea, su interpretación sobre lo bello y lo feo, lo trágico y lo cómico, lo elevado y lo bajo, lo heroico y lo trivial. El objetivo del arte y de la actividad artística es la aprehensión estética (introspección, introyección, asimilación) de esa realidad y su consecuente reconstrucción o reinterpretación en forma de imágenes estéticas.

Una concepción del valor estético a tono con el paradigma del pensamiento complejo, del que se derivan las actitudes y criterios a que se ha hecho referencia, incluye una serie de invariantes que han sido identificadas por Marrero Caballero (2010, p. 67-82); estas son:

I) Naturaleza omniobjetiva de los valores estéticos

2) Manifestación de la experiencia estética y de su valoración

3) Unidad senso-racional del valor

4) No linealidad de la interacción entre los componentes del sistema de donde emerge el valor

5) Predictibilidad limitada a un horizonte del conocimiento

6) Dialógica de lo individual y lo social

Así entendido, el arte es una actividad exclusivamente humana, el ser humano es el único portador de todas las relaciones estéticas, los objetos no son bellos por sí mismos, sino porque despiertan en el ser 
humano sentimientos y sensaciones estéticas, que son resultado de su educación y del medio social en que se desarrolla.

En todo este proceso, que transcurre desde la realidad externa hacia lo interno del individuo y de allí retorna a la propia realidad, pero transformado en imagen artística se produce la interrelación de categorías estéticas (Vigotski, 1978), conceptos de máxima amplitud, entre los que pueden citarse, como más importantes, la unidad y contradicción de lo concreto y lo abstracto, de lo lógico y lo sensorial, de lo general y lo particular, del fenómeno y la esencia y del contenido y la forma. La armonía y equilibrio entre estas categorías es un elemento determinante en la receptividad del hecho artístico, que debe complementarse con el grado de educación estética de los auditorios para comprender y valorar adecuadamente el producto artístico.

Las imágenes artísticas, portadoras de valores estéticos, son producto de condiciones o premisas de las que el artista es poseedor, esto es de sensibilidad artística y de maestría profesional, en las que se combinan tanto disposiciones naturales de la personalidad como habilidades y hábitos adquiridos mediante el estudio y la práctica. Pero el reconocimiento social de los valores estéticos de la obra de arte requiere que los públicos posean la sensibilidad y los conocimientos indispensables para apreciar en su justo valor las diversas manifestaciones artísticas. Y esto solo puede lograrse mediante la educación. Como señalara el célebre intelectual y patriota cubano José Martí, refiriéndose a la poesía “... tan autores son de ella los que la comprenden como los que la hacen” (Martí, I962, p. 285).

Como se ve, la función del arte puede resumirse en satisfacer las necesidades estéticas de los seres humanos, mediante obras que proporcionan un placer estético, enriquecimiento espiritual y satisfacción personal a partir de la recreación artística de la realidad en sus diversas formas de expresión. Entonces, el arte resulta no solo un contenido de la educación del ser humano, sino también un medio para educarlo, para ampliar su visión del mundo y de sí mismo, ahora desde la perspectiva de los valores estéticos. 
En este sentido es comprensible el papel que históricamente se ha reconocido a la educación estética (o apreciación del arte) como parte inseparable de la educación integral del ser humano, como componente indiscutible del proceso de humanización. Lo que fue reconocido por los filósofos de la antigüedad se ha mantenido como idea recurrente a lo largo de los diversos regímenes sociales, con independencia del grado en que pudiera materializarse en cada sociedad. Todos los grandes pedagogos, con independencia de su posición filosófica y de su compromiso de clase, Commenius o Vives, Pestalozzi o Rosseau, Dewey o Klinberg, Piaget o Vigotski, Suchodolski o Barragán, coinciden en la importancia de la educación estética y promueven su inclusión en los currículos escolares. El célebre intelectual ruso del siglo XIX V. G. Bielinski expresó con mucha belleza la utilidad de la apreciación del arte:

[...] es la condición de la dignidad del hombre, solamente ante ella es posible la inteligencia, solamente con ella los científicos pueden erguirse hasta las ideas mundiales, ella entiende la naturaleza desde todos sus ángulos, sólo con ella los ciudadanos pueden sacrificarse por su patria y sus esperanzas propias, sólo con ella el hombre puede hacer de la vida una hazaña y no ceder bajo su peso (citado por Verb, I970, p. 212).

Coincidiendo en esta interpretación, la política educacional de la revolución cubana, desde su inicio, concedió gran importancia a la educación estética de toda la población. Como expresara Arando Hart, ministro de Cultura, en la reunión de ministros de los países socialistas de I980:

[...] la educación estética constituye un elemento esencial de nuestra política, de nuestra ideología. El valor del arte, de la belleza y, consiguientemente, de la estética, tiene significación en la medida en que responde a una necesidad en el desarrollo de la sociedad (Hart, I980, p. I96). 
Para la pedagogía cubana la educación estética del individuo es una resultante de la educación artística, siendo esta última el medio más importante para desarrollarla, aunque no el único.

La educación estética se desarrolla en dos direcciones diferentes, que se distinguen por sus objetivos específicos. La primera dirección de la educación estética -que también puede denominarse apreciación del arte-implica la formación de valores estéticos en todos los ciudadanos, y comienza desde los primeros grados de la enseñanza primaria. Su objetivo fundamental es la creación de sentimientos y actitudes estéticas en los niños y niñas, que les permitan apreciar y disfrutar los valores estéticos de las obras del arte universal.

La segunda, más conocida como educación o enseñanza artística, está dedicada a la formación profesional en las diversas artes, mediante escuelas, academias o conservatorios especializados que otorgan diferentes grados de formación. En el sistema educativo cubano funcionan las Escuelas Vocacionales de Arte, que impartían los niveles Elemental y Medio, y la Universidad de las Artes, antiguamente el Instituto Superior de Arte, que impartía el nivel Superior.

Es muy llamativo que el programa de la Hoja de Ruta para la Educación Artística, presentada por la UNESCO en la Conferencia Mundial sobre este tema (UNESCO, 2006) resulta muy cercano, aunque no totalmente coincidente, con el reconocimiento de estas direcciones en el sistema educativo cubano, que data de los años sesenta del pasado siglo. Así, el mencionado documento declara:

[...] existen dos enfoques principales de la educación artística que pueden implementarse al mismo tiempo y no necesariamente por separado. En concreto, las artes se pueden enseñar, I) como materias individuales en las que se imparten distintas disciplinas artísticas a fin de desarrollar las competencias artísticas, la sensibilidad y la apreciación de las artes por los estudiantes, o 2) utilizar como método de enseñanza 
y aprendizaje e incluir dimensiones artísticas y culturales en todas las asignaturas del currículo (UNESCO, 2006, p. 5).

En cualquier caso, entre estas dos direcciones o expresiones de la relación arte-educación-individuo debe considerarse también la necesaria formación de maestros y profesores de arte, profesionales especializados que asumirían la dirección del proceso educativo, tanto de la formación artística profesional en las escuelas de arte como de la educación estética en el resto de las instituciones educativas. Si bien resultaría óptimo que todos los profesores de arte fueran a la vez artistas con una práctica profesional reconocida, no parece factible que la mayoría de los artistas profesionales estuvieran en condiciones de, ni interesados en asumir el reto de la enseñanza, que puede perjudicar el desarrollo de sus respectivas carreras. No es menos cierto que la enseñanza artística puede exhibir múltiples ejemplos de excelentes profesores que nunca han tenido resultados notables en el arte, más allá del que logran sus propios alumnos -algo que también ocurre con los críticos e historiadores de arte-. Es evidente la gran complejidad de este problema, en el que no caben fórmulas predeterminadas.

La forma en que una nación se preocupa por la educación estética de sus ciudadanos es una expresión muy concreta del nivel de desarrollo alcanzado por la sociedad, no tanto en lo económico, que resulta importante, pues de él depende la disponibilidad de recursos para su atención, sino mucho más del sistema de valores que la sustenta, de su ideal del hombre y de su bienestar, de su sentido de humanidad y felicidad, que necesariamente pasa por sus conceptos de belleza, armonía, equilibrio, ritmo, proporción, contraste, complemento, y tantos otros que constituyen el arsenal de la estética. Un mundo mejor

34 también tiene que ser más bello, como más justo, más humano. Los mejores sistemas educativos serán aquellos que promuevan la formación integral del ser humano, incluyendo los recursos para su apropiación crítica de la realidad, desde criterios éticos y estéticos, que le permitan expresar de manera creativa sus cualidades personales. Cualquier sistema que descuida la educación estética de sus ciudadanos, privilegiando los aspectos técnicos, o de cualquier otra 
índole, está limitando la naturaleza humana de los sujetos, reduciéndolos exclusivamente a la categoría de fuerza de trabajo, y, seguramente, reforzando la idea de que el arte y la cultura artística constituyen parcelas reservadas para ciertos sectores de la sociedad.

La educación estética, en sus dos direcciones, contribuye decisivamente a la conservación, desarrollo y divulgación del patrimonio cultural de la nación, tanto como los productos del arte, que le sirven como expresión concreta de los sentimientos, actitudes y valores estéticos de sus ciudadanos. México es reconocido en todo el mundo a través de los murales de Siqueiros, Orozco y Rivera, de los dramáticos cuadros de Frida Kahlo, de la literatura de Juan Rulfo, del cine del Indio Fernández, y esto es así porque cada uno de ellos supo expresar las esencias de su pueblo, su historia y sus tradiciones, el ser nacionales les permitió convertirse en universales, como lo son Martí, Darío o Neruda, Carpentier, García Márquez o Benedetti, Borges o Vargas Llosa, Lam o Botero, con independencia de sus posiciones políticas o momentos históricos en que desarrollaron su creación artística. La educación artística tiene que recoger ese legado y transmitirlo a las nuevas generaciones, para enriquecer su vida con valores que trascienden los límites de la sobrevivencia material y que, en definitiva, son los que nos distinguen como seres humanos.

De la misma forma, aunque en sentido inverso, Cervantes o Shakespeare, como Esquilo, Sófocles y Eurípides desde mucho antes, son reconocidos universalmente porque fueron capaces de tratar los temas fundamentales de la existencia y de los sentimientos del ser humano a través de situaciones y personajes que trascienden el tiempo y el espacio. El mensaje desgarrador del Guernica de Picasso es tan comprensible para todos los públicos, como el de perfección y sosiego que transmite el David de Miguel Ángel. El placer estético que producen las sinfonías de Mozart y Beethoven es tan elevado como que dan las óperas de Verdi o Puccini, con independencia del país o la lengua de quien la escucha. Este es el verdadero sentido del arte: su trascendencia, en la medida en que sea capaz de asumir los valores estéticos nacionales y universales, individuales y colectivos, temporales 
y permanentes. Pero la comprensión del arte requiere de un grado de identificación con esos valores estéticos, en todas sus connotaciones, de una educación estética que haga del ser humano un individuo más pleno y feliz.

Como expresa el filósofo colombiano Javier Domínguez:

La formación que proporciona el arte, de acuerdo con su autonomía para lo bello, lo relevante y, cuando se justifique, lo intrascendente del juego insustancial, es una formación de humanidad en el ciudadano, que puede resumirse en tres aspectos: placer, juicio propio y crítica (Domínguez, 2004, p. I2I).

Una nación será más rica cuanto más plenos sean sus ciudadanos, cuanto mayor sean las posibilidades reales de cada uno de ellos de disfrutar de los productos de la actividad productiva, tanto material como espiritual, de los resultados de la ciencia y la técnica, de la creatividad y la imaginación que se traduce en la creación artística en cualquiera de sus formas de expresión. A vez, un ciudadano será más pleno cuanto mejor preparado esté para disfrutar de todos esos bienes, he aquí donde se inserta, con pleno derecho, la educación estética y artística. A riesgo de parecer excesivamente comprometidos con esta idea, retomamos al mismo autor:

Como cultura política (entendida en su sentido más amplio) el gran aporte de la experiencia estética del arte es la formación y el refinamiento de la cultura del gusto, de la cultura del pensamiento y el juicio autónomos, de la cultura de la crítica como debate vivo y abierto. Es una formación cuyo ethos impera, no con la implacabilidad de las normas, sino con la espontaneidad de una segunda naturaleza (Domínguez, 2004, p. I2I).

Esa segunda naturaleza (la del individuo culto) solo puede ser resultado de la educación estética y del esfuerzo que la sociedad realice para hacerla accesible a todos. 


\section{Conclusiones}

A modo de conclusión, es evidente la diversidad de criterios en cuanto a la consideración como mímesis, o sea, reproducción del mundo en imágenes artísticas, las concepciones actualmente dominantes rebajan la relación de la obra de arte con la realidad, en favor de las perceptibles cualidades estéticas del objeto artístico en sí mismo o de la relación entre la obra de arte y la mente creativa que la originó.

La función del arte puede resumirse en satisfacer las necesidades estéticas de los seres humanos, mediante obras que proporcionan un placer estético, enriquecimiento espiritual y satisfacción personal a partir de la recreación artística de la realidad en sus diversas formas de expresión, resulta no solo un contenido de la educación del ser humano, sino también un medio para educarlo, para ampliar su visión del mundo y de sí mismo, ahora desde la perspectiva de los valores estéticos.

Si el arte es una actividad exclusivamente humana, el ser humano es el único portador de todas las relaciones estéticas, sentimientos y sensaciones estéticas, que son resultado de la educación y del medio social en que se desarrolla. La forma en que una nación se preocupa por la educación estética de sus ciudadanos es una expresión muy concreta del nivel de desarrollo alcanzado por la sociedad, del sistema de valores que la sustenta, de su ideal del hombre y de su bienestar, de su sentido de humanidad y felicidad, que necesariamente pasa por sus conceptos de belleza, armonía, equilibrio, ritmo, proporción, contraste, complemento, y tantos otros que constituyen el arsenal de la estética. Un mundo mejor también tiene que ser más bello, como más justo, para ser más humano. El sentido de plenitud del ser humano depende tanto de las posibilidades de satisfacer sus necesidades materiales como las espirituales, lo que le otorga un nuevo sentido a la vida, una nueva naturaleza. La educación estética, tanto para la apreciación del arte como para la creación artística, debe prepararlo para ese disfrute del arte, que forma parte inseparable de su existencia. 


\section{Referencias}

Agosti, H. (1963). Defensa del realismo. Buenos Aires: Editorial Lautaro.

Arias, S. (200I). Algunas consideraciones acerca de la educación estética del hombre. En P. Guadarrama (comp.). Filosofía y Sociedad, tomo II, (479-486). Editorial Félix Varela.

Batjin, M. M. (1986). Problemas literarios y artísticos. La Habana: Arte y Literatura.

Colectivo de autores. (1984). Pedagogía. La Habana: Pueblo y Educación.

Collingwood, R. G. (1938). The Principles of Art. Oxford.

Dickie, G. (1974). Art and Aesthetic. New York: Ithaca.

Domínguez, J. (2004). Juicio estético y cultura política. En G. Vargas y L. G. Cárdenas (eds.). Filosofía, Pedagogía y enseñanza de la Filosofía (pp. I09-I2I). Bogotá: Universidad Pedagógica Nacional.

Gramsci, A. (196I). Literatura y vida nacional. Buenos Aires: Lautaro.

Hart, A. (1980). Informe a la Reunión de Ministros de Cultura de los Países Socialistas. Moscú.

Honderich, T. (200I). Enciclopedia Oxford de Filosofía. Madrid: Tecnos.

Iudin, P., y Rosenthal, M. (I98I). Diccionario Filosófico. La Habana: Editorial Política.

Lúkacs, G. (1963). Significación social del realismo crítico. México: ERA.

Marrero Caballero, M. (2004). Aproximación a una comprensión compleja de los valores estéticos. En Educación, Cultura y Complejidad. Belo Horizonte: Editorial CAPES. 
Martí, J. (1962). Obras Completas (tomo V). La Habana: Editora Nacional de Cuba.

Marx, C. (1980). Manuscritos económico filosóficos de I844. Moscú: Progreso.

Marx, C. y Engels, F. (1957). Sobre el Arte (en dos tomos). Moscú: Editorial Iskustvo.

Navarro, D. (1986). Cultura y marxismo. La Habana: Letras Cubanas.

Ovsianikov, M. F. (1986). Estética marxista. La Habana: Arte y Literatura.

Ponce, A. (196I). Educación y lucha de clases. La Habana: Imprenta Nacional de Cuba.

Ramos, G. (200I). Arte, hombre y sociedad. En P. Guadarrama (comp.), Filosofía y Sociedad, Tomo II (pp. 486-529). Editorial Félix Varela.

Rojas, M. (200I). Para una estética abierta. En P. Guadarrama (comp.) Filosofía y Sociedad, Tomo II (pp. 457-478). Editorial Félix Varela.

Sánchez Vázquez, A. (1973). Las ideas estéticas de Marx. La Habana: Instituto Cubano del Libro.

Sánchez Vázquez, A. (1980). Filosofía de la Praxis. Barcelona: Editorial Crítica.

Sánchez Vázquez, A. (1987). Ideología y realismo en Marx y Engels. En Marx y la contemporaneidad. La Habana: Editorial Ciencias Sociales.

Schúkina, G.I. (1980). Teoría y método de la educación comunista. La Habana: Pueblo y Educación. 
UNESCO. (2006). Hoja de Ruta para la Educación Artística. Conferencia Mundial sobre la Educación Artística. Lisboa: Organización de las Naciones Unidas para la Educación, la Ciencia y la Cultura.

Verb, M. A. (197I). La educación estética de los escolares de los grados superiores. Leningrado: Editorial Pedagógica.

Vigotski, L. S. (1978). Psicología del arte. Moscú: Editoril Iskutsvo.

Walton, K. (1990). Mimesis as make-believe. Massachusets: Cambridge.

White, J. (1990). Education and the Good Life. Londres.

Zis, A. (1976). Fundamentos de estética marxista. Moscú: Raduga.

${ }^{1}$ Véase la explicación de este proceso en los Manuscritos Económico Filosóficos de I844 (Marx, I980).

Este artículo se publica bajo una licencia de Creative Commons Reconocimiento-NoComercial 4.0 Internacional, y puede ser usados gratuitamente para fines no comerciales, dando los créditos a los autores y a la revista.

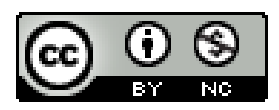

